NASA TECHNICAL MEMORANDUM

$\frac{\pi}{\frac{1}{\grave{x}}}$

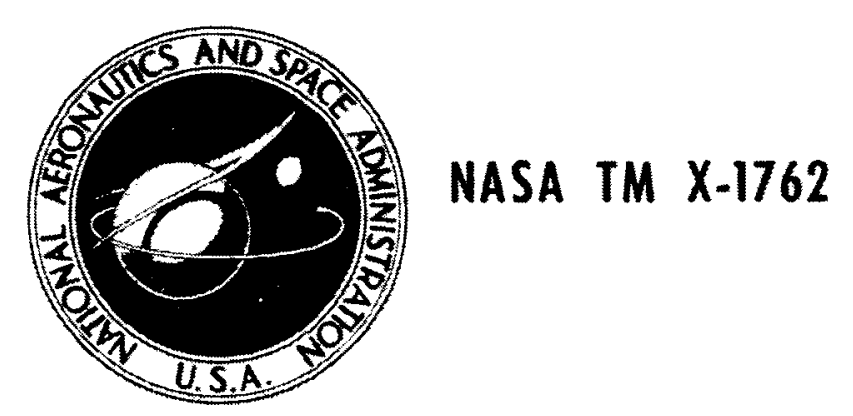

APPLICATION OF A MODIFIED

FAST FOURIER TRANSFORM

TO CALCULATE HUMAN OPERATOR

DESCRIBING FUNCTIONS

by Richard S. Shirley

Electronics Research Center

Cambridge, Mass.

NATIONAL AERONAUTICS AND SPACE AdMINISTRATION - WASHINGTON, D. C. - MARCH 1969 
NASA TM X-1762

\author{
APPLICATION OF A MODIFIED FAST \\ FOURIER TRANSFORM TO CALCULATE \\ HUMAN OPERATOR DESCRIBING FUNCTIONS
}

By Richard S. Shirley

Electronics Research Center

Cambridge, Mass.

NATIONAL AERONAUTICS AND SPACE ADMINISTRATION

For sale by the Clearinghouse for Federal Scientific and Technical Information Springfield, Virginio 22151 - CFSTI price $\$ 3.00$ 


\section{APPLICATION OF A MODIFIED FAST \\ FOURIER TRANSFORM TO CALCULATE \\ HUMAN OPERATOR DESCRIBING FUNCTIONS}

By Richard S. Shirley

Electronics Research Center

\section{SUMMARY}

A version of the fast Fourier transform (FFT) is used in a hybrid computer program to permit processing of tracking data to yield the human operator's describing function almost immediately after the period of data-taking. The use of the FFT allows the final calculation time required to process 216 seconds of tracking data to be reduced to 3 seconds from the 10 minutes previously required on the same computer. The algorithm used permits the bulk of the analysis of the data to be performed while the data are being taken, and does not require all the data to be present in core before processing begins.

\section{TABLE OF SYMBOLS}

a the index of summation for the additive portion of the FFT

$A_{k} \quad$ a constant which weights the sinusoids composing the system input, see Table I

${ }^{A} \mathrm{xk} \quad$ the real part of the truncated Fourier transform of $x(t)$ at the frequency $\omega_{k}$, given by

$$
\int_{0}^{T} x(t) \cos \left(\omega_{k} t\right) d t
$$

$\mathrm{B}_{\mathrm{xk}}$ the imaginary part of the truncated Fourier transform of $x(t)$ at the frequency $\omega_{k}$, given by

$$
\int_{0}^{T} x(t) \sin \left(\omega_{k} t\right) d t
$$

c a subscript referring to the output of the human operator at the control stick (see Figures 1 and 4)

$c(n \Delta t)$ the data samples taken at the human operator's output 
TABLE OF SYMBOLS (cont'd)

$\mathrm{D}_{\mathrm{k}} \quad$ an integer devisable by 4 used to determine the input frequencies

e a subscript referring to the input to the human operator at the oscilloscope (see Figures 1 and 4)

e (n $\Delta t)$ the data samples taken at the human operator input

FFT . Fast Fourier Transform

$F_{x}\left(\omega_{k}\right)$ the truncated Fourier transform of $x(t)$ at the frequency $\omega_{k}$, given by

$$
\int_{0}^{T} x(t) e^{-j \omega t} d t
$$

h a subscript used to denote frequencies between the input frequencies, equal to $1,2,3, \ldots$

i a subscript referring to the system input (see Figures 1 and 4)

$i(n \Delta t)$ the system input equals

$$
\sum_{k=1}^{14} A_{k} \cdot \sin \left(\omega_{k} n \Delta t\right)
$$

$j$ the square root of -1 .

k a subscript used to denote the input frequencies, equal to $1,2,3, \ldots, 14$

$m(n \Delta t)$ the data samples taken at the system output

$\mathrm{n}$ the index of summation for the multiplicative portion of the FFT

N the number of data samples taken, 10,800

$\mathrm{T}$ - the period of data-taking, equal to 216 seconds

$Y_{C}(\omega)$ the dynamics of the controlled element (see Figures 1 and 4)

$Y_{p}(\omega)$ the linear portion of the quasi-linear describing function 

$\beta_{\mathbf{k}}$
$\left(\mathrm{N} / \mathrm{D}_{\mathrm{k}}\right)-1$
$\gamma_{\mathbf{k}}$
$\left(D_{k} / 4\right)-1$
$\Delta \mathrm{t}$
the time increment between interrupts, and hence the time between data samples, equals .02 sec $w_{k} \quad$ the frequencies of the sinusoids comprising the system
input, see Table I
$w_{h} \quad$ frequencies between the $\omega_{k}$ 's
$\Phi_{i c}(\omega)$ the cross power spectral density between the human operator's output and the system input $\Phi_{\text {ie }}(\omega)$ the cross power spectral density between the human
operator's input and the system input
$\Phi_{\mathrm{nn}}(\omega)$ the continuous power spectral density of the human
operator's remnant

\section{INTRODUCTION}

Only recently have dynamic models of the human operator been used effectively in the design of man-vehicle systems. This is due partially to a lack of understanding of the human operator and also to the difficulty and expense of experimentally determining values for the various parameters of existing models. Improvements in computers and computational techniques are overcoming these difficulties, and already it is possible to bring about significant improvements in a man-vehicle system through the use of pilot models in preliminary design (refs. 1 and 2). This paper describes a computational technique which reduces greatly the cost of obtaining values permitting the use of a current pilot model, i.e., the quasi-linear describing function.

One way to characterize the behavior of a human operator in a continuous tracking task is by a quasi-linear describing function, which consists of a linear describing function and a remnant. The linear describing function is the average frequency response of the human operator, $i . e .$, his amplitude ratio and phase as a function of frequency. The remnant, characterized by a continuous power spectral density, is that portion of the human operator's output which is not linearly correlated with his input. The total output of the human operator is the sum of the remnant and the output of the linear describing function* (see Figure 1).

\footnotetext{
*Examples of human operator describing functions are shown in Figures 2 and 3 .
} 


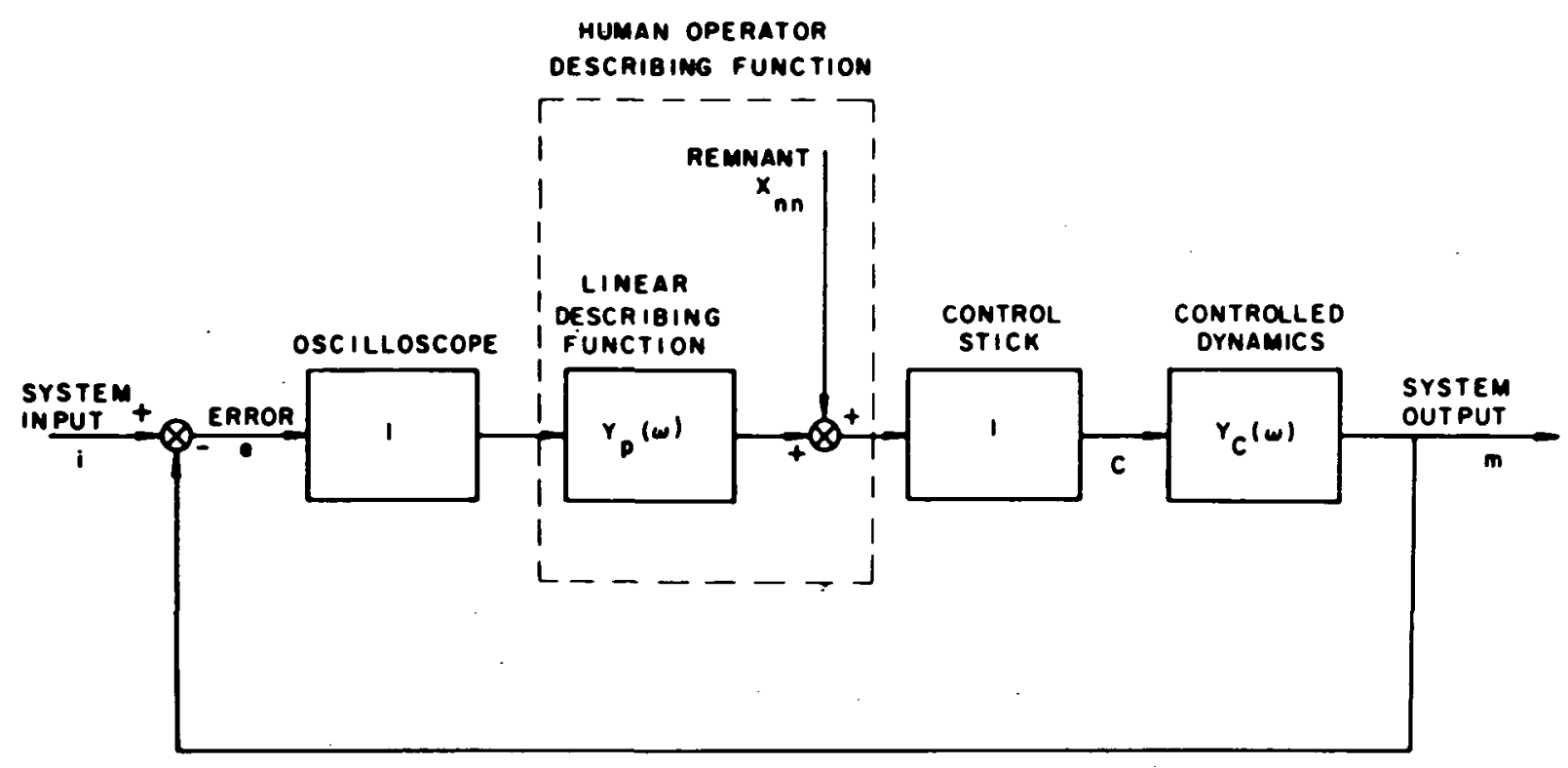

Figure 1.- Block diagram of the human operator in a compensatory tracking system.

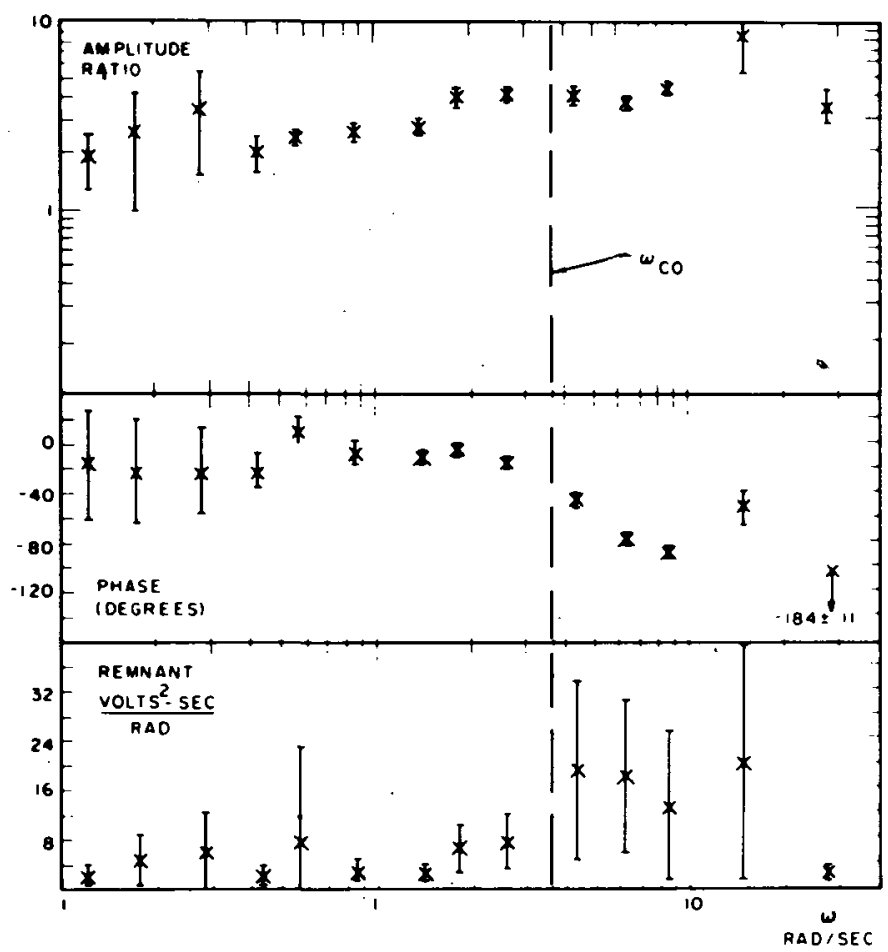

Figure 2.- $Y_{p}(\omega)$ measured for $Y_{C}(s)=1 / s$ 
A direct way to measure describing functions in the laboratory involves the use of a hybrid computer and the method of Fourier coefficients. The method of Fourier coefficients has been extensively investigated and is described in detail (ref. 3). It will be briefly outlined here for completeness. The human operator is placed in a control loop, possibly as shown in Figures 1 and 4. The system input, a sum of sinusoids of known amplitude, phase, and frequency is updated every $\Delta t$ seconds; simultaneously, data are taken at the human operator's input and output. At the end of $T$ seconds, the sampled values of the human operator's input and output are processed as follows:

$$
\begin{aligned}
& A_{c k}=\frac{\Delta t}{T} \sum_{n=1}^{N} c(n \Delta t) \cos \left(\omega_{k} n \Delta t\right) \\
& B_{C k}=\frac{\Delta t}{T} \sum_{n=1}^{N} c(n \Delta t) \sin \left(\omega_{k} n \Delta t\right) \\
& A_{e k}=\frac{\Delta t}{T} \sum_{n=1}^{N} e(n \Delta t) \cos \left(\omega_{k} n \Delta t\right) \\
& B_{e k}=\frac{\Delta t}{T} \sum_{n=1}^{N} e(n \Delta t) \sin \left(\omega_{k} n \Delta t\right) \\
& F_{C}\left(\omega_{k}\right)=A_{c k}-j B_{c k} \\
& F_{e}\left(\omega_{k}\right)=A_{e k}-j B_{e k} \\
& Y_{p}\left(\omega_{k}\right) \\
& Y_{p}\left(\omega_{k}\right)=\frac{F_{c}\left(\omega_{k}\right)}{F_{e}\left(\omega_{k}\right)}
\end{aligned}
$$




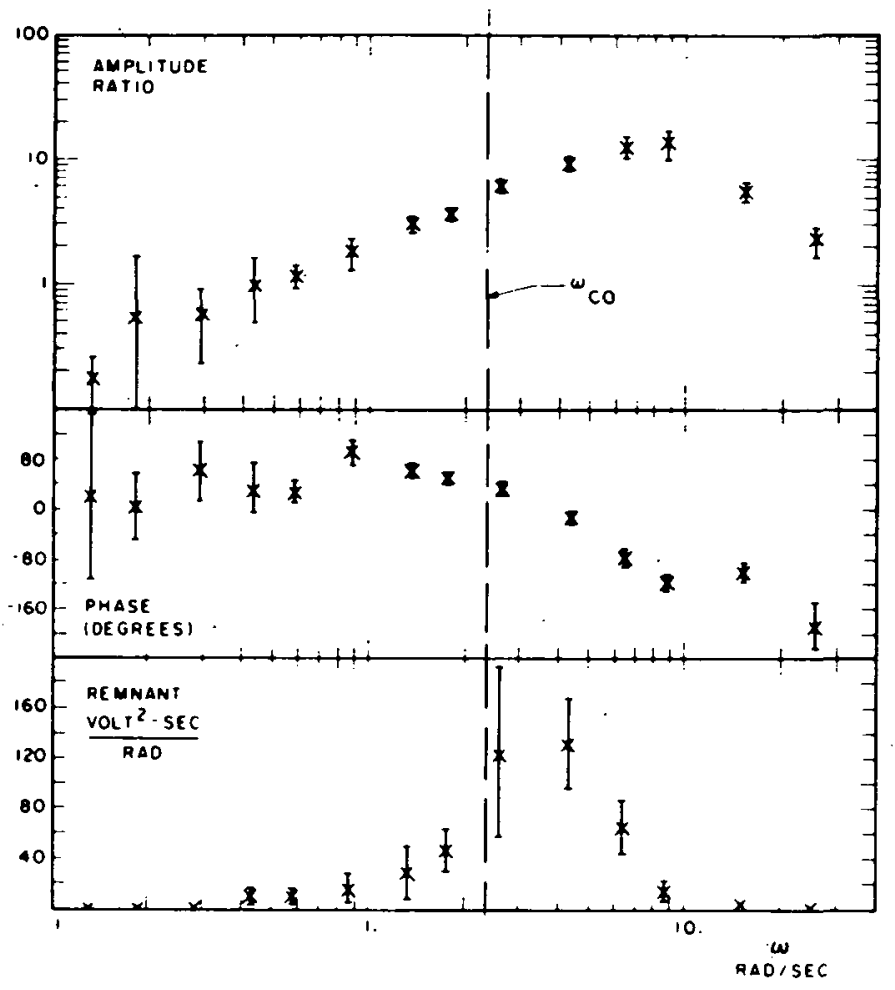

Figure 3.- $Y_{p}(\omega)$ measured for $Y_{C}(s)=1 / s^{2}$

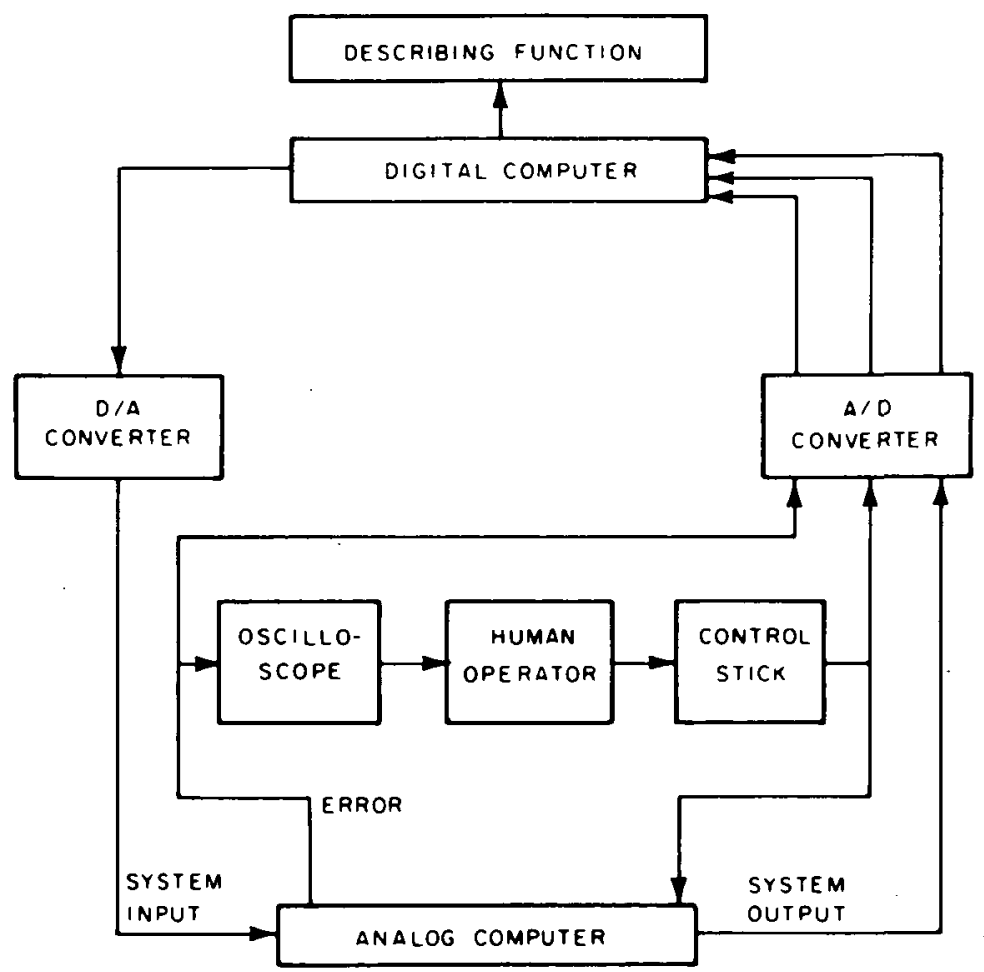

Figure 4.- Flow diagram of the human operator in a compensatory tracking system. 


$$
\begin{aligned}
& \left|Y_{p}\left(\omega_{k}\right)\right|=\left[\frac{A_{C k}^{2}+B_{c k}^{2}}{A_{e k}^{2}+B_{e k}^{2}}\right]^{1 / 2} \\
& \Phi_{C C}\left(\omega_{h}\right)=\frac{1}{2 \pi T}\left|F_{C}\left(\omega_{h}\right)\right|^{2} \\
& \Phi_{n n}\left(\omega_{h}\right)=\Phi_{C c}\left(\omega_{h}\right)\left|1+Y_{p} Y_{C}\left(\omega_{h}\right)\right|^{2}
\end{aligned}
$$

where the $\omega_{k}$ 's are the input frequencies, and the $\omega_{h}$ 's lie between the $\omega_{k}$ 's.

This paper describes how a version of the fast Fourier transform (FFT) is used to compute human operator describing functions, or more specifically, how a version of the FFT is used to solve Eqs. (1) through (4), while the data samples, $c(n \Delta t)$ and e $(n \Delta t)$, are being taken. The FFT is an algorithm which greatly reduces the time required to calculate the truncated Fourier transform, or periodogram, of a sampled time signal. The savings are obtained by replacing calculations which involve trigonometric functions or multiplications with simple additions. The replacement is accomplished by taking advantage of the symmetries of the sine and cosine functions, and by further taking advantage of relationships between the frequencies at which the Fourier analysis is performed.

\section{THE VERSION OF THE FFT USED}

The version of the FFT used takes advantage only of the symmetries of the sine and cosine functions. It does not take advantage of the relationships among the frequencies at which the Fourier analysis is performed. By not using the complete version of the FFT, it becomes possible to perform the bulk of the data-processing during the $\Delta t$ seconds between interrupts while the experiment is still in process. The requirement that the data be in core before processing, or even that the data fit in core, is avoided. The following derivation of the algorithm used will make this point clearer. It should be noted that before the FFT was used it was not possible to perform the calculations between interrupts because the computation time required was over two and a half times greater than that which was available. 
It is desired to evaluate Eqs. (1) through (4) using a digital computer. In order to permit the use of the FFT, the input frequencies, $\omega_{k}$, will be restricted to

$$
\omega_{k}=\frac{2 \pi}{D_{k} \Delta t}
$$

where the $D_{k}$ are chosen from $4,8,12,16$, etc. The method of Fourier coefficients further requires that the ratio $N / D_{k}$ be an integer (where $\mathrm{N}$ is the number of data samples taken at intervals $\Delta t)$. The derivation for $A_{e k}$ and $B_{e k}$ is identical to the derivation which follows for $A_{\mathrm{ck}}$ and $B_{\mathrm{Ck}}$.

Using the identities

$$
\begin{aligned}
& \sin (\theta+2 \pi)=\sin \theta, \text { and } \\
& \cos (\theta+2 \pi)=\cos \theta
\end{aligned}
$$

or

$$
\left.\begin{array}{l}
\sin \left(\omega_{k} \Delta t\right)=\sin \left[\left(a D_{k}+1\right) \omega_{k} \Delta t\right] \\
\cos \left(\omega_{k} \Delta t\right)=\cos \left[\left(a D_{k}+1\right) \omega_{k} \Delta t\right]
\end{array}\right\} \quad a=0,1,2,3, \ldots
$$

permits Eqs. (1) and (2) to be rewritten as

$$
\begin{aligned}
& A_{c k}=\frac{\Delta t}{T} \sum_{n=1}^{D_{k}}\left[\cos \left(\omega_{k} n \Delta t\right) \sum_{a=0}^{\beta_{k}} c\left[\Delta t\left(n+a D_{k}\right)\right]\right] \\
& B_{c k}=\frac{\Delta t}{T} \sum_{n=1}^{D_{k}}\left[\sin \left(\omega_{k} n \Delta t\right) \sum_{a=0}^{\beta_{k}} c\left[\Delta t\left(n+a D_{k}\right)\right]\right]
\end{aligned}
$$

where $\beta_{k}=\left(N / D_{k}\right)-1$. The identities

$$
\begin{aligned}
& \sin (\theta-\pi)=-\sin \theta, \text { and } \\
& \cos (\theta-\pi)=\cos \theta
\end{aligned}
$$


or

$$
\begin{aligned}
& \sin \left[\omega_{k} \Delta t\left(n-\frac{D_{k}}{2}\right)\right]=-\sin \left(\omega_{k} n \Delta t\right) \\
& \cos \left[\omega_{k} \Delta t\left(n-\frac{D_{k}}{2}\right)\right]=\cos \left(\omega_{k} n \Delta t\right)
\end{aligned}
$$

permit Eqs. (12) and (13) to be written as

$$
\begin{aligned}
A_{c k}= & \frac{\Delta t}{T} \sum_{n=1}^{D_{k} / 2}\left[\operatorname { c o s } ( \omega _ { k } n \Delta t ) \sum _ { a = 0 } ^ { B _ { k } } \left\{c\left[\Delta t\left(n+a D_{k}\right)\right]\right.\right. \\
& \left.\left.-c\left[\Delta t\left(n+\frac{D_{k}}{2}+a D_{k}\right)\right]\right\}\right] \\
B_{c k}= & \frac{\Delta t}{T} \sum_{n=1}^{D_{k} / 2}\left[\operatorname { s i n } ( \omega _ { k } n \Delta t ) \sum _ { a = 0 } ^ { B _ { k } } \left\{c\left[\Delta t\left(n+a D_{k}\right)\right]\right.\right. \\
& \left.\left.-c\left[\Delta t\left(n+\frac{D_{k}}{2}+a D_{k}\right)\right]\right\}\right]
\end{aligned}
$$

Finally, the identities $\sin (-\theta)=-\sin \theta, \cos (-\theta)=\cos \theta$, $\sin (\pi / 2)=\cos (\pi)=1$, and $\sin (\pi)=\cos (\pi / 2)=0$ permit Eqs. (14) and (15) to be written as

$$
\begin{aligned}
A_{c k}= & \frac{\Delta t}{T} \sum_{n=1}^{\gamma_{k}}\left[\operatorname { c o s } ( \omega _ { k } n \Delta t ) \sum _ { a = 0 } ^ { B _ { k } } \left\{c\left[\Delta t\left(n+a D_{k}\right)\right]-c\left[\Delta t\left(n+\frac{D_{k}}{2}+a D_{k}\right)\right]\right.\right. \\
& \left.\left.-c\left[\Delta t\left(\frac{D_{k}}{2}-n+a D_{k}\right)\right]+c\left[\Delta t\left(\frac{D_{k}}{2}-n+\frac{D_{k}}{2}+a D_{k}\right)\right]\right\}\right] \\
& -\frac{\Delta t}{T} \sum_{a=0}^{\beta}\left\{c\left[\Delta t\left(\frac{D_{k}}{2}+a D_{k}\right)\right]-c\left[\Delta t\left(\frac{D_{k}}{2}+\frac{D_{k}}{2}+a D_{k}\right)\right]\right\}
\end{aligned}
$$




$$
\begin{aligned}
B_{c k}= & \frac{\Delta t}{T}\left[\sum _ { n = 1 } ^ { \gamma _ { k } } \operatorname { s i n } ( \omega _ { k } n \Delta t ) \sum _ { a = 0 } ^ { \beta _ { k } } \left\{c\left[\Delta t\left(n+a D_{k}\right)\right]-c\left[\Delta t\left(n+\frac{D_{k}}{2}+a D_{k}\right)\right]\right.\right. \\
& \left.\left.+c\left[\Delta t\left(\frac{D_{k}}{2}-n+a D_{k}\right)\right]-c\left[\Delta t\left(\frac{D_{k}}{2}-n+\frac{D_{k}}{2}+a D_{k}\right)\right]\right\}\right] \\
& +\frac{\Delta t}{T} \sum_{a=0}^{B_{k}}\left\{c\left[\Delta t\left(\frac{D_{k}}{4}+a D_{k}\right)\right]-c\left[\Delta t\left(\frac{D_{k}}{4}+\frac{D_{k}}{2}+a D_{k}\right)\right]\right\}
\end{aligned}
$$

where $\gamma_{k}=\left(D_{k} / 4\right)-1$. Equations (16) and (17) represent the algorithm used in the hybrid program. The summation over "a" is performed between interrupts during the experiment and is called the "additive portion" of the FFT. At the end of the data-taking period, the summation over $n$ (called the "multiplicative portion" of the FFT) and the calculation of the human operator's describing function [using Eqs. (8) and (9)], can be performed in less than three seconds.

The hybrid computer program is written in a Fortran IV language which includes hybrid commands. The program is listed in Appendix A. Table I lists the values of the experimental parameters, including those which characterize the system input. Figure 5 is a flow diagram of the additive portion of the FFT. Figure 6 shows a flow diagram of the hybrid program, and lists the time taken by each part of the program, both for the FFT version and for the version written the old way [directly computing Eqs. (1) through (4)]. As shown in Figure 6, the FFT permits a saving of nearly ten minutes per run, effectively reducing the run time to the time required to take the data and print the results.

\section{RESULTS}

An initial check of the hybrid program was made by taking measurements across known filters. The results shown in Figures 7 and 8 are quite accurate, and are repeatable.

Measurements were then taken of the author's tracking performance in a control loop, as shown in Figures 1 and 4 . Ten runs were made with each of the controlled elements, $1 / \mathrm{s}$ and $1 / s^{2}$. The describing functions shown in Figures 2 and 3 are comparable with established results (ref. 3 ). 


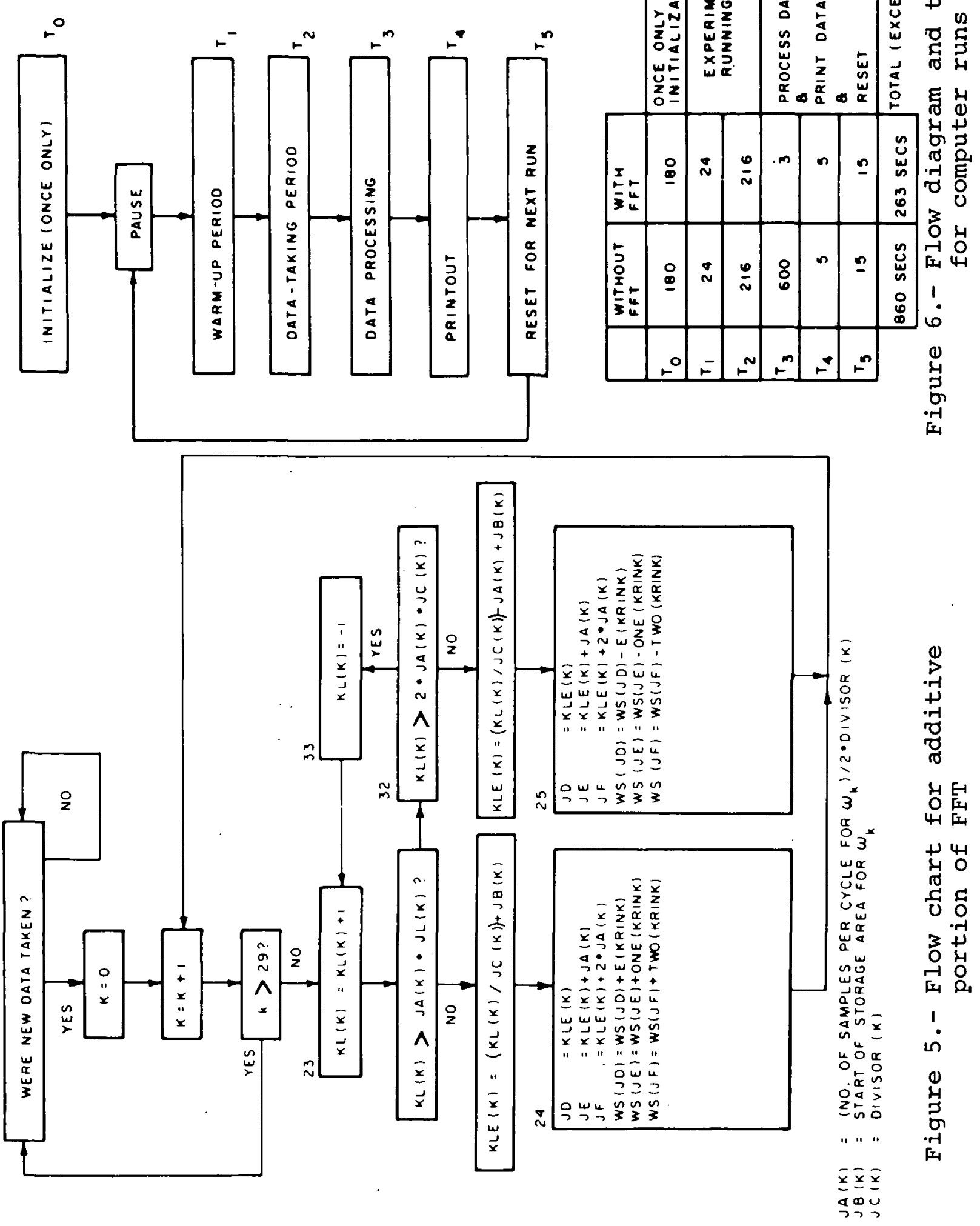




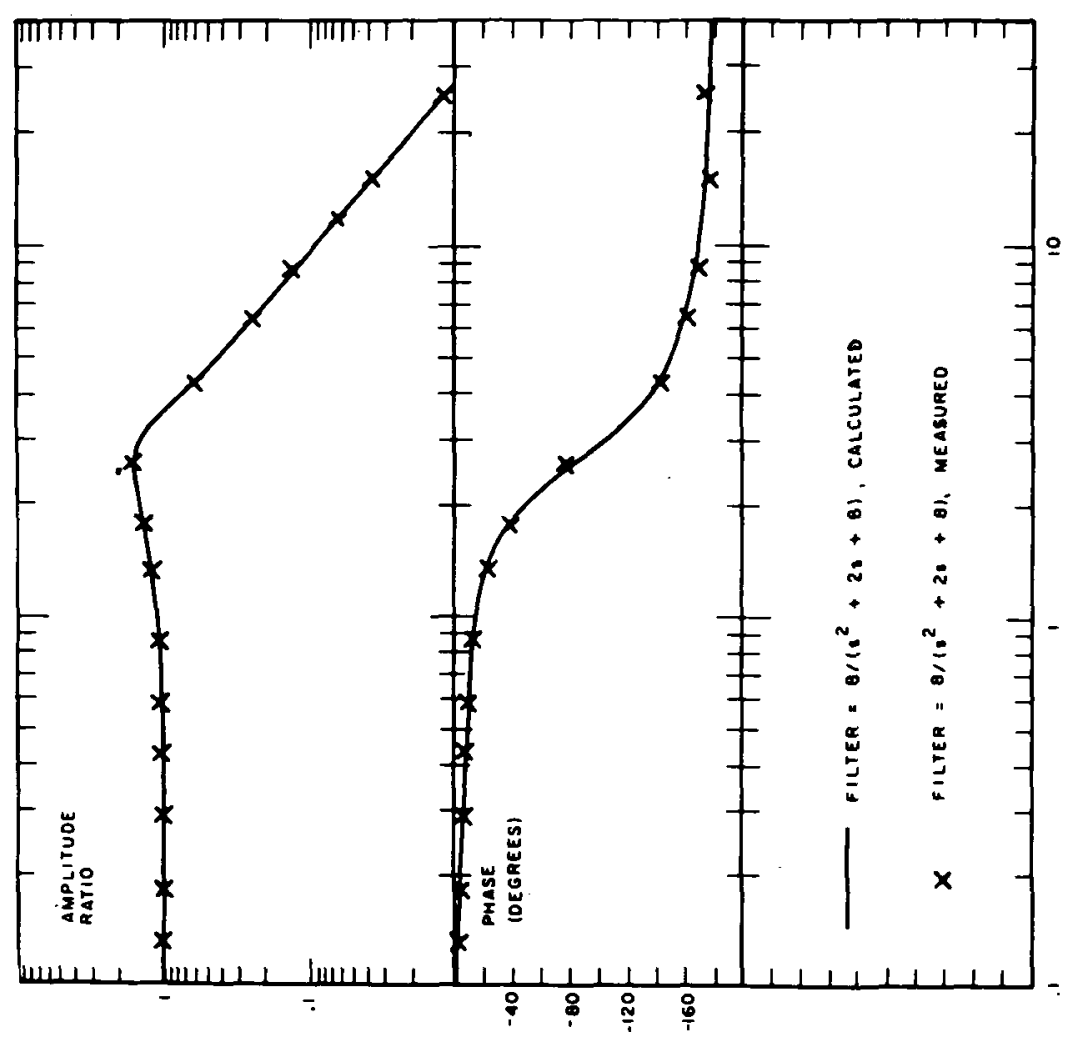

Oy

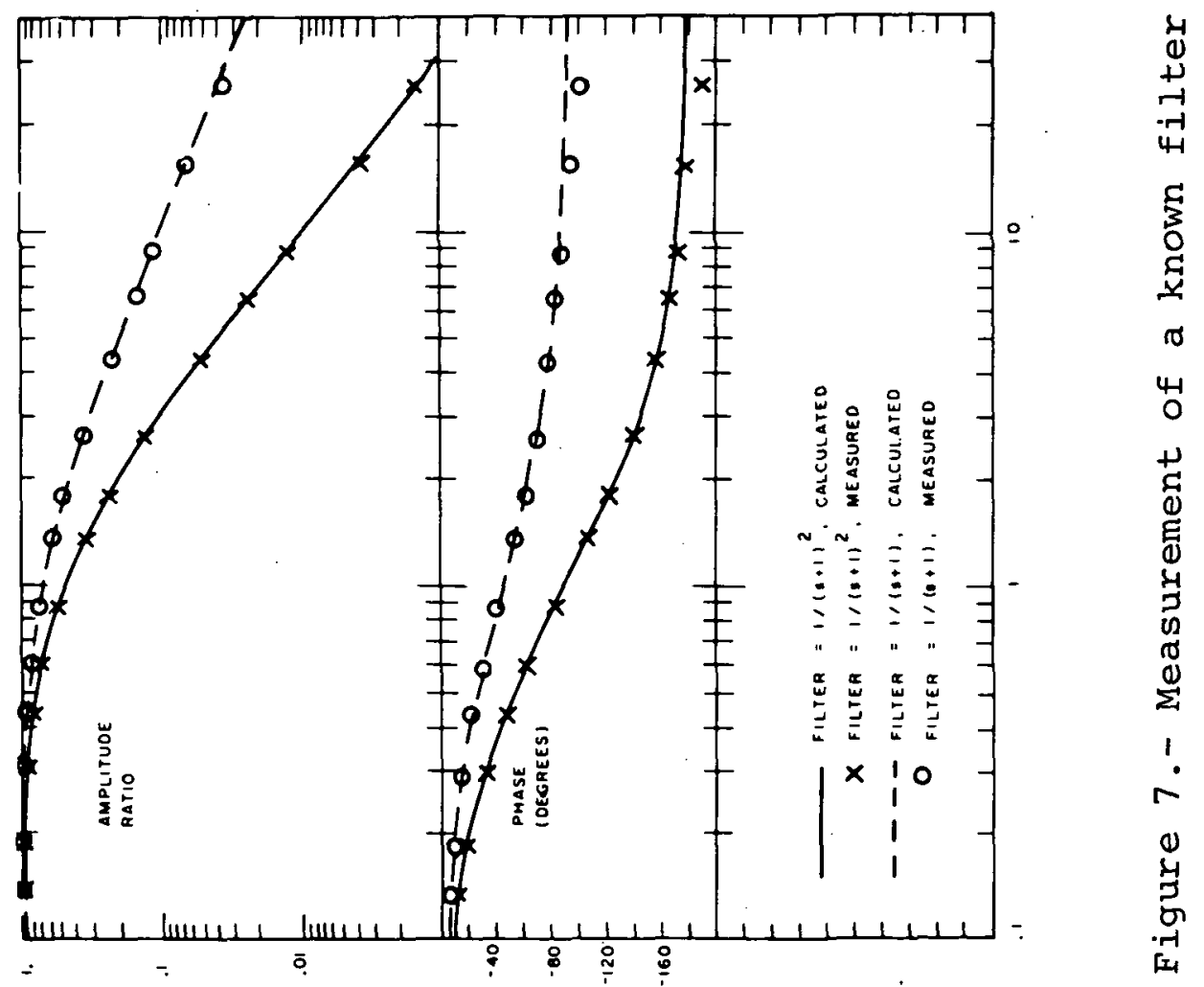


PARAMETER VALUES USED FOR THE HYBRID PROGRAM

$$
\begin{aligned}
& \begin{array}{|c|c|c|c|c|c|}
\hline k & \begin{array}{c}
A_{k} \\
\text { volts }
\end{array} & \begin{array}{c}
\omega_{k} \\
\text { rad/sec }
\end{array} & k & \begin{array}{c}
A_{k} \\
\text { volts }
\end{array} & \begin{array}{c}
\omega_{k} \\
\mathrm{rad} / \mathrm{sec}
\end{array} \\
\hline 1 & .2 & 26.18 & 8 & -1 . & 1.309 \\
2 & -.2 & 15.71 & 9 & 1 . & .8727 \\
3 & .2 & 8.727 & 10 & -1 . & .5818 \\
4 & -.2 & 6.545 & 11 & 1 . & .4363 \\
5 & .2 & 4.363 & 12 & -1 . & .2909 \\
6 & -1 . & 2.618 & 13 & 1 . & .1745 \\
7 & 1 . & 1.745 & 14 & -1 . & .1164 \\
\hline
\end{array} \\
& \Delta t=\text { time between interrupts }=.02 \mathrm{sec} \\
& \mathrm{T}_{1}=\text { warm-up time before data-taking }=24 \mathrm{sec} \\
& \mathrm{T}=\text { period of data-taking }=216 \mathrm{sec} \\
& i(n \Delta t)=\text { system input }=\sum_{k=1}^{14} A_{k} \sin \left(\omega_{k} n \Delta t\right)
\end{aligned}
$$

No comparison is made between results for the programs with and without the FFT (on Figures $2,3,7,8$ ) because the results are identical, as is shown analytically in the derivation of Eqs. (16) and (17). The comparison between the computation times for the two programs (Figure 6) however, indicates the substantial savings obtained by using the FFT. The only penalty paid for the reduced computational time is an increase in the complexity of the written Fortran program, as shown in Appendix A.

National Aeronautics and Space Administration Electronics Research Center

Cambridge, Massachusetts, November 1968 $125-19-01-11-25$ 
1. McRuer, D. T., et al.: New Approaches to Human-Pilot/Vehicle Dynamic Analysis. AFFDL-TR-67-150, Feb. 1968.

2. Elkind, J. I., et al.: An Optimal Control Method for Predicting Control Characteristics and Display Requirements for Manned-Vehicle Systems. AFFDL-TR-67-187, Apr. 1968.

3. McRuer, D. T., et al.: Human Pilot Dynamics in Compensatory Systems. AFFDL-TR-65-15, July 1965.

4. Taylor, L. W., Jr.: Discussion of Spectral Human Response Analysis. NASA-University Annual Conference on Manual Control, Feb. 1966.

National Aeronautics and Space Administration

Electronics Research Center

Cambridge, Massachusetts, December, 1968

125-19-01-11-25 


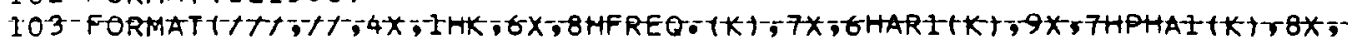
$16 H A R 2(K), 9 X, 7 H P H A 2(K), / 1,(15,5 E 15.4))$

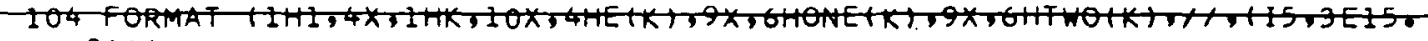
24)1

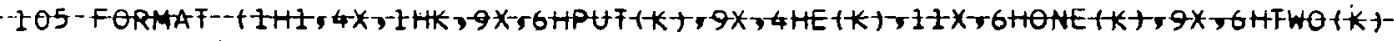
$1, / 1,([5,4 E 15.4))$

- -1OG-FORMAF--HIHI, 4 -

107 FORMAT $(1 / 1,10 X, 8$ HPUTSO $=, 1 E 15.4,1,10 X, 8 H E R R S O=, 1 E 15.4,10 X$,

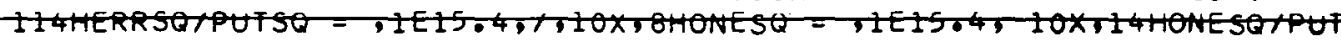
$250=, 1 E 15.4,1,10 X, 8$ HTWOSO $=, 1 E 15.4,10 X, 14 \mathrm{HTWOSQ} / \mathrm{PUTSQ}=, 1 \mathrm{E} 15.41$ 


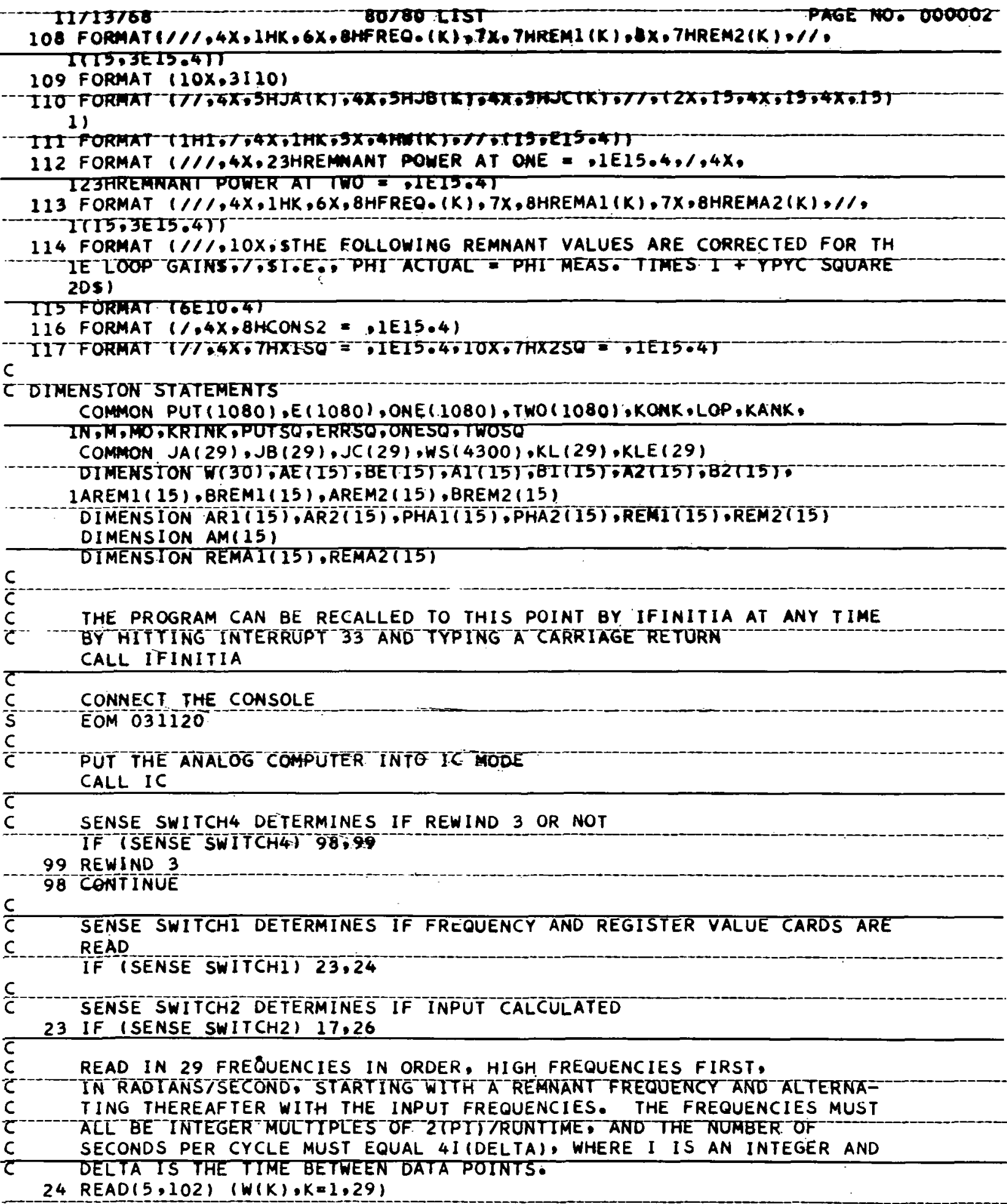




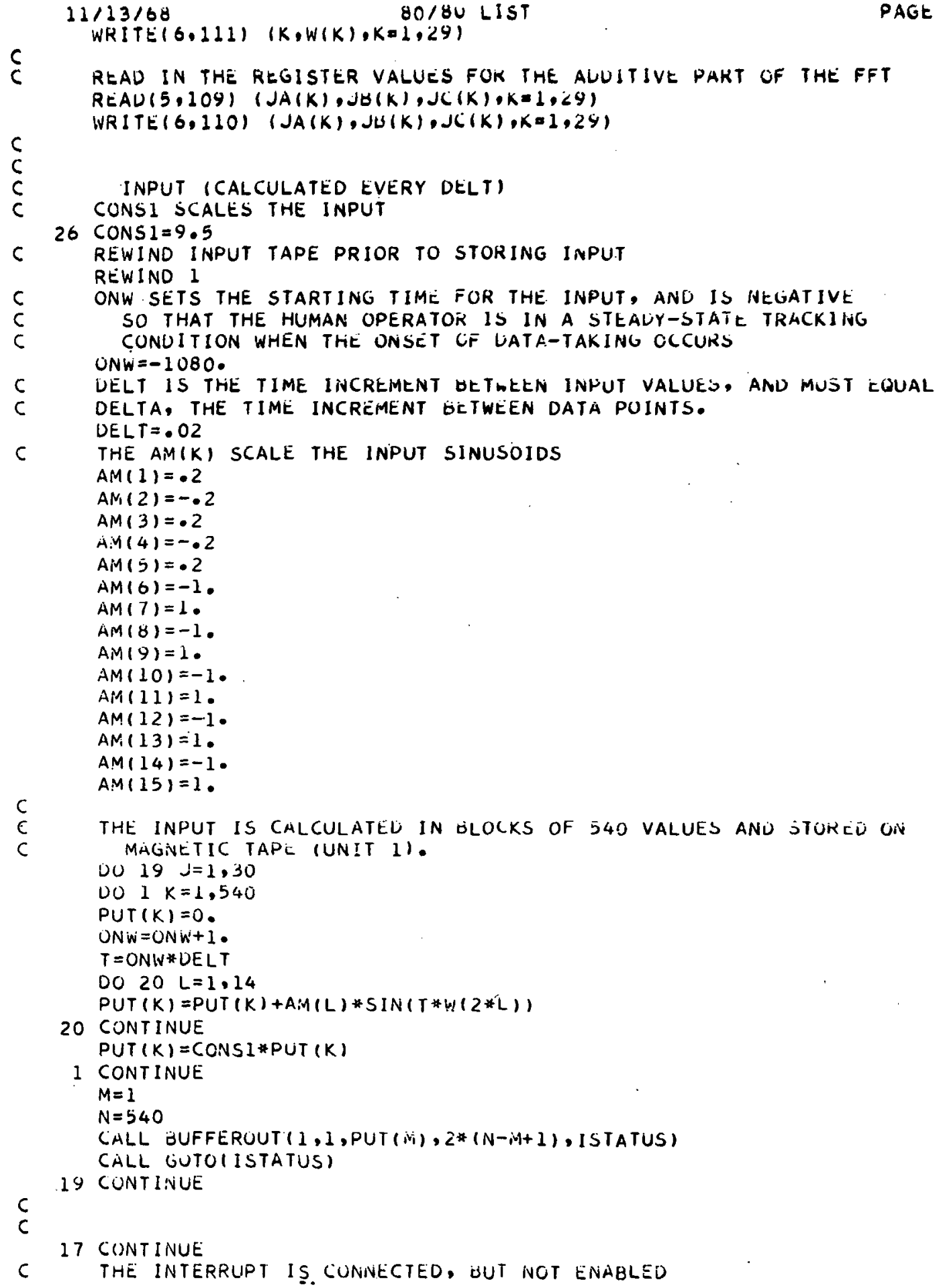


INITIALIZE FOR THE RUN

ZERO THE BUFFER AREAS

DO $92 \mathrm{~K}=1,1080$

$\operatorname{PUTT}(K)=0$.

$E(K)=0$.

$\operatorname{ONE}(K)=0$.

$T W O(K)=0$.

92 CONTINUE

ZERO THE UATA TAPE

REWINO 2

DO $91 \quad K=1,90$

$N=340$

$M=1$

CALL BUFFEROUT $(2,1, E(M), 2 *(N-M+1)$, ISTATUS

CALL GOTOIISTATUSI

91 CONTINUE

THE MAGNeTIC TAPE UNITS ARE INITIALIZLU, UNit I FOR THE INPUT, AND UNIT 2 FUR THE DATA.

RERIND 1

REWINO 2

ZLRO THE REGISTERS WHERE THE FOURIER COEFFICIENTS ARE TU B'E CALCULATEU.

DO $31 K=1,15$

$A E(K)=0$.

$B E(K)=0$.

$A I(K)=0$.

bl $(K)=0$.

$A 2(K)=0$.

$\nabla 2(K)=0$.

$\operatorname{AREMI}(K)=0$.

$\triangle R E M I(K)=0$.

$\operatorname{AREM} 2 \cdot(K)=0$.

DREM $2(K)=0$.

31 CUNTINUE

INITIALLIZE FOR THE ADUITIVE PART OF THE FFT

DO 10 NOW $=1,29$

$K L(N O W)=-1$

10 CONTINUE

DO 14 NOW $=1,4300$

WS $($ NOW $)=0$.

14 CUNTINUE

INITIALLIZE THE CUUINTERS FUK THE RUN

KRINK IS A CUUNTER TO DETERMINE THE LOCATION FRUM WHICH THE NEXT INPUT VALUE SHOULD DE TAKEN FRUI:

$K R I N K=0$

KONK CCURTS THE INTERRUPTS, DETERMIIVES WHEN THE ONSET OF LATA- 
$1 / 13 / 68$

$80 / 80$ LIST

PAGE NC. OCLOOS

KONK $=0$

C KANK IS THE TALF REGISTCR CUUNTER, 1 TO 540

$K A N K=0$

MO UETERMINES WHICT HALF OU THIE INPUT UUFFER IS GE ING USEU $M O=0$

8 IS A COUNTLR UN THE DATA USEO DURINÜ THE OATA-PRUCESSING $B=-1$.

$C$

$C$

LOP IS THE FLAG SET BY INTR TO END DATA-TAKINC

LOP $=0$

PUTSO AND ERRSO ARE THE INTEGRAL SOJARE INFUT AIVD ERKUR

PUTSQ $=0$.

$E R R S Q=0$

ONESO $=0$.

TWOSC $=\mathrm{C}$.

$X 15 U=0$

$X 250=0$

INITIALLIZE INPUT UUFFER FOR TITE RUN, I.C., FILL UUTH HALVES $M=1$

WITH INPUT VALLUES

$i v=340$

CALL BUFFERIN(1, l, PUT(ivi), $\angle *(N-i *+1)$, ISTHTUS)

(ALL GOTUIISTATUS)

$M=541$

$N=1080$

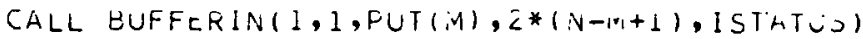

CALL GUTOIISTATUSI

$c$

WAIT TO START RUN ON SIGNAL FRÜM THE UPERATOP.

PAUSE

C

511 CONTINUE

SKS 0.30000

ORU 5135

GO TO 511

513 CONTINUE

$c$

PUT THE ANALUU CONPUTER INTU CONPUTE MUUL

CALL CUMPUTE

$c$

$\mathrm{C}$

ENABLE THE INTTERRUPT

EUM 031032

I I CONTINUE

CHECK TO SEE IF IT IS THE END OF DATA-TAKINO

IF (LOP.EO.I) GO TO 2

C IT IS NOT THE END OF DATA TAKING, WAIT FOR INTERRUPT

Gu TO il

$c$

$\check{c}$

IT IS THE ENO UF DATA TAKINU, UU ON

2 CONTINUE

C

TURN OFF THE INTERRUPT

EOM 031033

PUT THE ANALOE COMPUTER INTU THE HOLD MCUE 
$11 / 13 / 68$

$80 \% 80$ LIST

PAGE NO. 000006

TAKE THE INTEGRAL SOUARE MEASURES

CALL ADL ( 4, PUTSO,EKRSU,ONESU, TWUSO, X1SO, 2250$)$

C PUT THE ANALOG COMPUTER INTU IL MODE

CALL IC

C

C

c

SENSE SWITCH3 DETERMINES WHETHER TO PROCESS THE DATA AND TYPE

THE RESULTS, OR WHETHER TU RE-INITIALLIZE FOR THE NEXT RUN IF (SENSE SWITCH3) 17,22

C

22 CONTINUE

THE FULLOWING SAVES THE LAST 5-O DATA POINTS

$N=1080$

$M=541$

CALL BUFFEROUT $(2,1, E(M), 2 *(N-M+1)$, ISTAIUS)

CALL GOTO(ISTATUS)

CALL BUFFEROUT $(2,1, \operatorname{ONE}(M), 2 *(N-M+1)$, ISTATUS $)$

CALL GOTO(ISTATUS)

CALL BUFFEROUT $(2,1, T W O(M), 2 *(N-M+1)$, ISTATUS)

(ALL GOTO(ISTATUS)

$\mathrm{C}$

$c$

THE FOLLOWING PERMITS A TOTAL OR PARTIAL TAPE UUMP IF (SENSE SWITCH5) 89,90

89 REWINU 1

REWINU 2

$N=540$

$M=1$

CALL BUFFERIN $(1,1, P U T(M), 2 *(N-M+1)$, ISTATUS)

CALL GOTOIISTATUS)

$N=1080$

$M=541$

CALL BUFFERIN $(1,1, P U T(M), 2 *(N-M+1)$, ISTATUS $)$

(ALL GOTO(ISTATUS)

WRITE $(6.106)(\mathrm{J}, P U T(J), J=1,1080)$

C GU PAST THE INITIAL SPURIOUS DATA POINTS ICAUSEL BY INTERRUPT

C ROUTINE).

$M=1$

$N=540$

$0016 \mathrm{~J}=1.3$

CALL BUFFERIN(2,1,t $(M), 2 *(N-M+1), 1 S T A T U S)$

CALL GOTOIISTATUS)

16 CONTINUE

NC DETERMINES EXTLNT OF THE DUMP

$\mathrm{NO}=3$

DC $88 \mathrm{~K}=1$, NO

CALL 3UFFERIN $(1,1, P U T(M), 2 *(N-M+1)$, ISTATUS )

CALL COTEIISTATUS)

CALL ZUFFERIN $(2, I, E(M), 2 *(N-M+1)$, ISTATUS

CALL GUTOIISTATUS)

CALL BUFFERIN $(2,1$, ONE $(M), 2 *(N-1 \cdot 1+1)$, ISTATUS)

CALL GOTOIISTATUS)

CALL BUFFERIN $(2,1$, TWO $(M), 2 *(N-M+1)$, ISTATUS)

CALL GOTO(ISTATUSI

$L=(K-1) * 540$ 


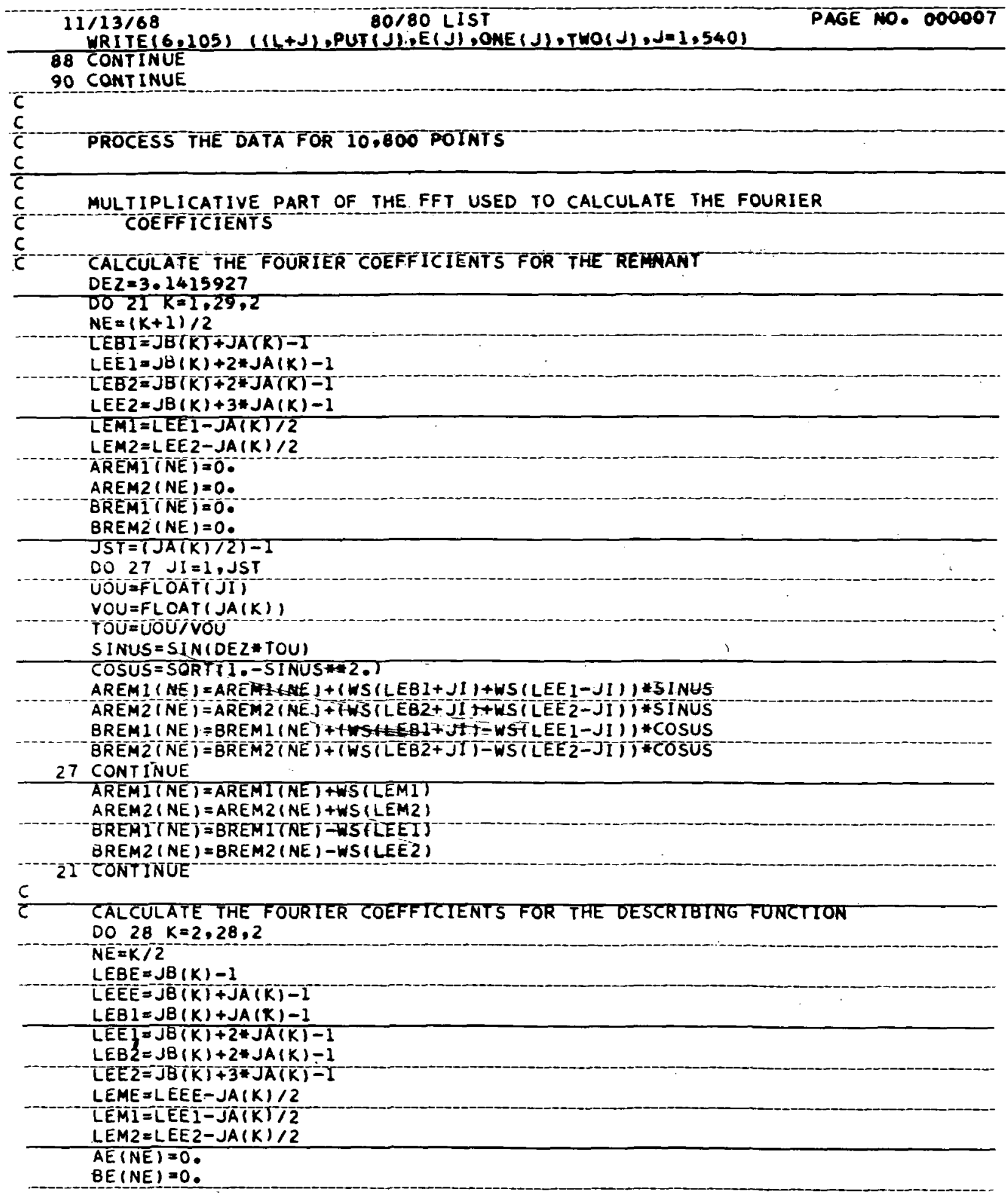




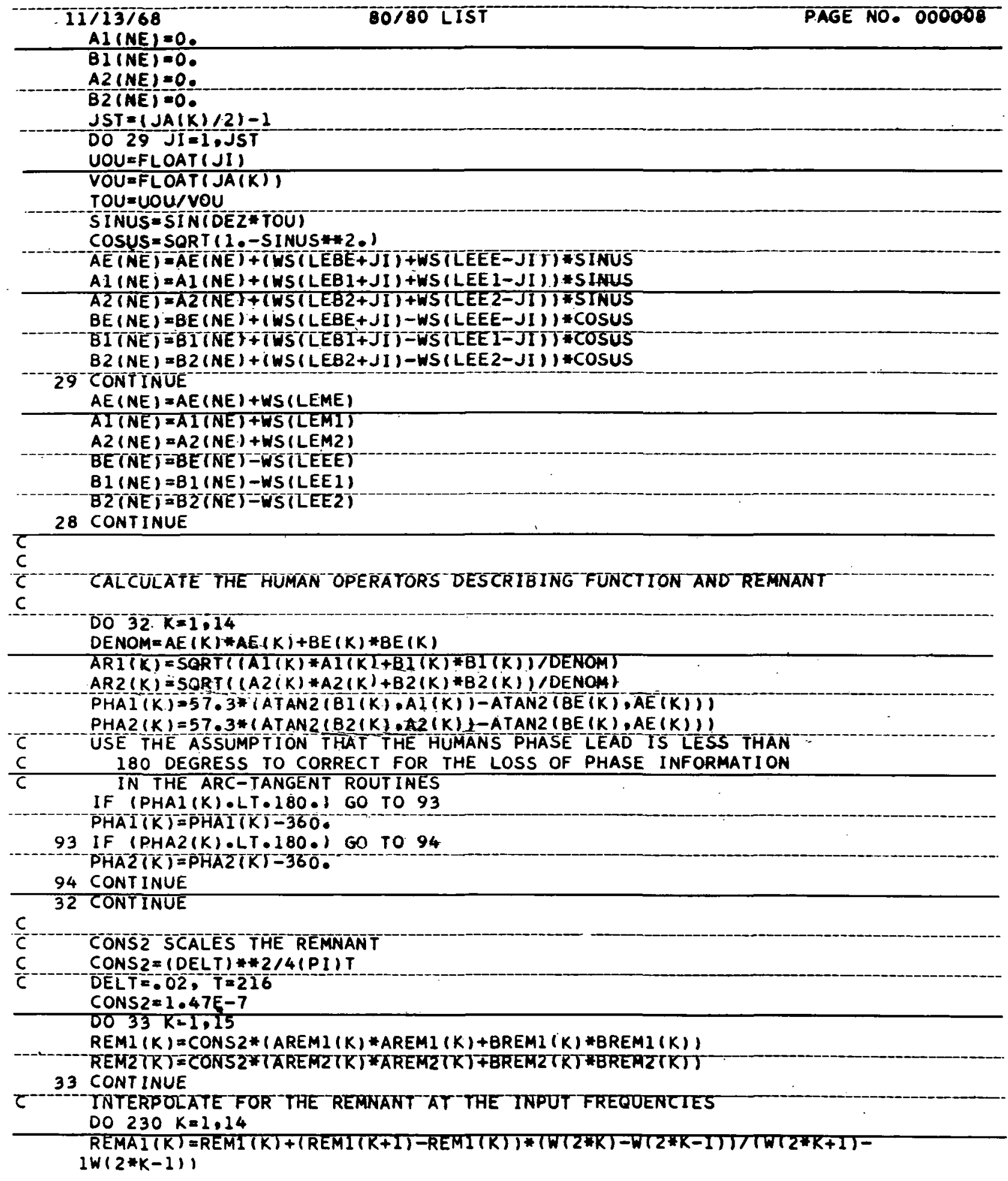


$11 / 13 / 68$

IW(2*K-1T)

230 CONTINUE

C

CALCULATE THE REMNANT POWER

REMPW $1=0$.

REMPW2 $=0$.

DO. $231 \quad K=1,14$

REMPW $1=R E M P W 1+R E M A I(K) *(W(2 * K-1)-W(2 * K+1))$

REMPW $2=R E M P W 2+R E M A 2(K) *(W(2 * K-1)-W(2 * K+1))$

231 CONTINUE

C

WRITE OUT THE FOURIER COEFFICIENTS OF THE SYSTEM ERROR (E), THE

HUMANS OUTPUT (ONE), AND OF THE SYSTEM OUTPUT (TWO).

WRITE $(6,100)(K, W(2 * K), A E(K), B E(K), A 1(K), B](K), A 2(K), B 2(K), K=1,14)$

C WRITE OUT THE FOURIER COEFFICIENTS OF THE REMNANT AT THE HUMANS

C OUTPUT (ONE), AND AT THE SYSTEM OUTPUT (TWO). WRITE $(6,101)(K, W(2 * K-1)$, AREMI(K),BREMI $(K), A R E M 2(K), B R E M 2(K), K=1,1$

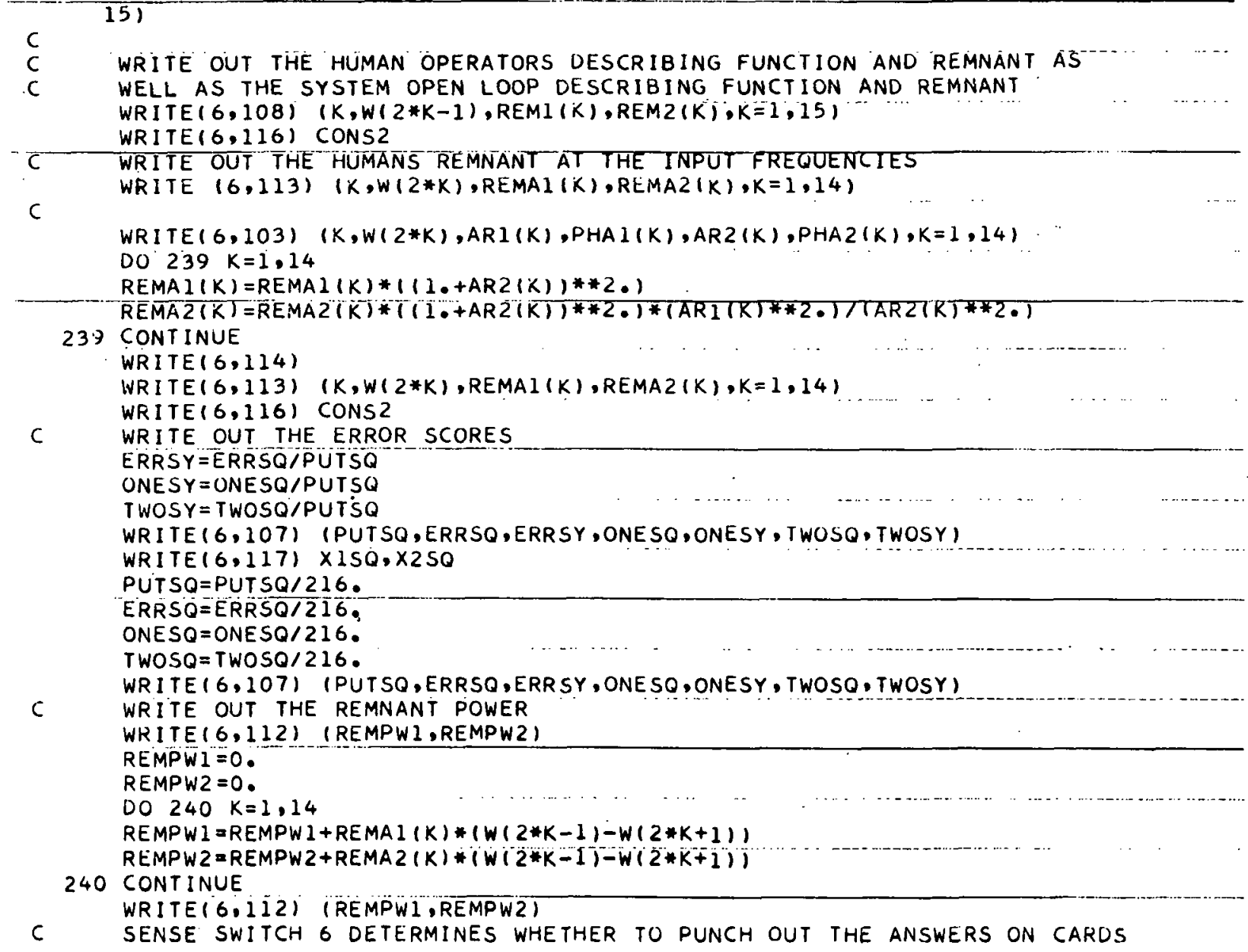


$11 / 13 / 68$

IF (SENSE SWITCH6) 35,36

$80 / 80$ LIST

PAGE NU. OOVOIO

PUNCH OUT THE DATA ON CARDS, 14 CARDS WITH AR1,PHA1,AR2,PHA2, REMA1, AND REMA2, PLUS 1 CARO WITH PUTSQ, ERRSU, ONESU, TWUSO, REMPW 1, AND REMPW2.

35 WRITE $(7,115)$ (ARI (K), PHAI (K), AR2 (K),PHA2 (K),REMA1 (K),REMA2 $(K), K=1$, 1141

WRITE $(7,115)$ (PUTSO,ERRSG, ONESO, TWOSQ, REMPW 1,REMPW2)

36 CONTINUE

c

c

$\mathrm{C}$

$C$

REWIND 2

REWIND 1

$M=1$

THE FOLLOWING STORES EITHER ONE(M) OR TWO(M) ON UNIT 3 FOR LATER PROCESSING FOR THE REMNANT

SENSE SWITCH4 DETERMINES WHETHER TO SAVE ONE(M) OR TWO(M)

IF (SENSE SWITCH4) 95,97

$N=540$

C THE FOLLOWING AVOIDS THE SPURIOUS DATA POINTS

DO $521 \quad K=1,3$

CALL BUFFERIN $(2,1, T W O(M), 2 *(N-M+1)$, ISTATUS $)$

CALL GOTO(ISTATUS)

521 CONTINUE

CALL BUFFERIN $(1,1, P U T(M), 2 *(N-M+1), 1$ STATUS $)$

CALL GOTO(ISTATUS)

CALL BUFFERIN $(1,1, P U T(M), 2 *(N-M+1)$, ISTATUS)

CALL GOTO(ISTATUS)

DO $96 K=1,20$

CALL BUFFERIN $\left.\left(1,1, P U T(M), 2^{*}(N-N)+1\right), I S T A T U S\right)$

CALL GOTO(ISTATUS)

CALL BUFFERIN $(2 ; 1, E(M), 2 *(N-M+1)$, ISTATUS $)$

CALL GOTO(ISTATUS)

CALL BUFFERIN $(2,1, \operatorname{ONE}(M), 2 *(N-M+1)$, ISTATUS)

CALL GOTO(ISTATUS)

CALL BUFFERIN $(2,1, T W O(M), 2 *(N-M+1)$, ISTATUS $)$

CALL GOTO(ISTATUS)

CALL BUFFEROUT $(3,1, \operatorname{PUT}(, M), 2 *(N-M+1)$, ISTATUS)

CALL GCTO(ISTATUS)

CALL BUFFEROUT $(3,1, E(M), 2 *(i N-M+1), 1 S T A T U S)$

CALL GCTOIISTATUS)

CALL BUFFEROUT $(3,1, O N E$ (M), $2 *(N-M+1)$, ISTATUS

CALL GCTO(ISTATUS)

CALL BUFFEROUT $(3,1$, TWO $(M), 2 *(N-M+1)$, ISTATUS $)$

(ALL GOTO(ISTATUS)

96 CONTINUE

95 CONTINUE

$\stackrel{c}{c}$

RETURN TO INITIALLIZE FOR THE NEXT RUN GO TO 17

200 STOP

INTERRUPT SUBROUTINE (INTERNAL)

INTR SERVICES THE INTERRUPT

SUBROUTINE INTR

C 
- KONK IS THE TOTAL COUNTER, I UN UP $K O N K=K O N K+1$

4 CALL DAL $(0$, PUT $(K R I N K))$

12 R:ETURN

1 IF (KONK.GT.11880). GO TO 5 IF (KANK. FE. 541 ) GO TO 6

8 (A'LL DAL $(0$, PUT (KRINK))

CALL AUL $(O, E(K R I N K)$, ONE (KRINK), TWO(KRINK))

ADUITIVÉ PART UF THE FAST FUURILR TRANSFURM

$K L=A$ COUNTER, j TOJ (L*JA $(K) * J C(K)-1)$

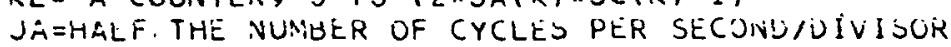

JD=RLGISTER START FOK LACH FREQUENCY

$J C=$ UIVISOR 'JSEQ ON hALF THE NUMEER OF SAPALES PER CYCLE TO GET JA

ADUITIVE PART OF THE FFT

AUD THE DATA INTO THE WS(K)

UC $27 \quad K=1.29$

$23 K L(K)=K L(K)+1$

$J N K=J A(K) * J(K)$

IF $(K L(K)$.GE.JAKK) UQ TU 32

$K L E(K)=K L(K) / J E(K)+J B(K)$

UU TO 24

$\because 2 J M K=2 * J \dot{A}(K) * J C(<)$

IF $(K L(K), G E \cdot J A K)$ OO TO 33

$K L E(K)=(K L(K) / J C(K))-J A(K)+J j(K)$

Gu TO 25

$33 K L(K)=-1$

Go TO $\angle 3$

$24 J U=K L \check{L}(K)$

$J E=K L E(K)+J A(K)$

$J F=K L=(K)+2 * J A(, K)$

NS $(J 0)=W S(j D)+E(K R I N K)$

WS $(J E)=W S(J E)+O N E(K R I$ iNK $)$

NS $(J F)=$ WS $(J F)+T W U(K R I N K)$

ن) $T=26$

$25 J D=K L E(K)$

$J E=K L E(K)+J A(K)$

$J==K L E(K)+2 * J A(K)$

WS $(J U)=i N S(J D)-E(K R$ I NK)

WJ (JE) $=v_{i} S(J E)$-ONE (KRINK:

WS $(J F)=N S(J F)-T$ iNO $(K R$ IINK $)$

20 CONTINUE

27 CUNTINUE

RETURiN

3 KANK = :

I $\vec{r}(M O \cdot G E \cdot 1)$ OO TU 7

$M \mathrm{~N}=\mathrm{i}$

$N=540$

$M=1$ 
$11 / 13 / 68 \quad 80 / 80$ LIST

PAGE NO. $0000 \overline{12}$

9 CALL BUFFERIN $(1,1, \operatorname{PUT}(M), 2 *(N-M+1)$, ISTATUS $)$ GO TO 4

$7 \mathrm{MO}=0$

$N=1080$

$M=541$

KRINK $=1$

GO TO 9

6 KANK $=1$

IF (MO.GE.I) GO TO 10

$\mathrm{MO}=1$

$N=540$

$M=1$

11 CALL BUFFERIN $(1,1, \operatorname{PUT}(M), 2 *(N-M+1)$, ISTATUS $)$

CALL BUFFEROUT $(2,1, E(M), 2 *(N-M+1)$, ISTATUS

CALL BUFFEROUT $(2,1, \operatorname{ONE}(M), 2 *(N-M+1), 1 S T A T U S)$

CALL BUFFEROUT $(2,1, T W O(M), 2 *(N-M+1), I S T A T U S)$ GO TO 8

$10 \mathrm{MO}=0$

$N=1080$

$M=541$

KRINK $=1$

GO TO 11

5 LOP $=1$

GO TO 12

C

SUBROUTINE GOTO (ISTATUS)

C SUBROUTINE (INTERNAL) TO HANDLE TAPE READ AND WRITES

7. GO TO $(6,4,5,5,5)$ ISTATUS

6 GO TO 7

5 WRITE $(102,200)$ ISTATUS

4 RETURN

200 FORMAT (\$BUFFERIN STATUS WORD $=\$, I 2$ ) END

* LOAD X

*DATA

39.269908

26.179938

19.634954

15.707963

13.089969

8.7266460

7.8539816

6.5449847

5.2359877

4. 3633230

3.1415927

2.6179939

2. 1816615

1.7453292

1.5707963

1.3089970

1. 0471975

. 87266462

.72722052

- 58177642

. 52359877 


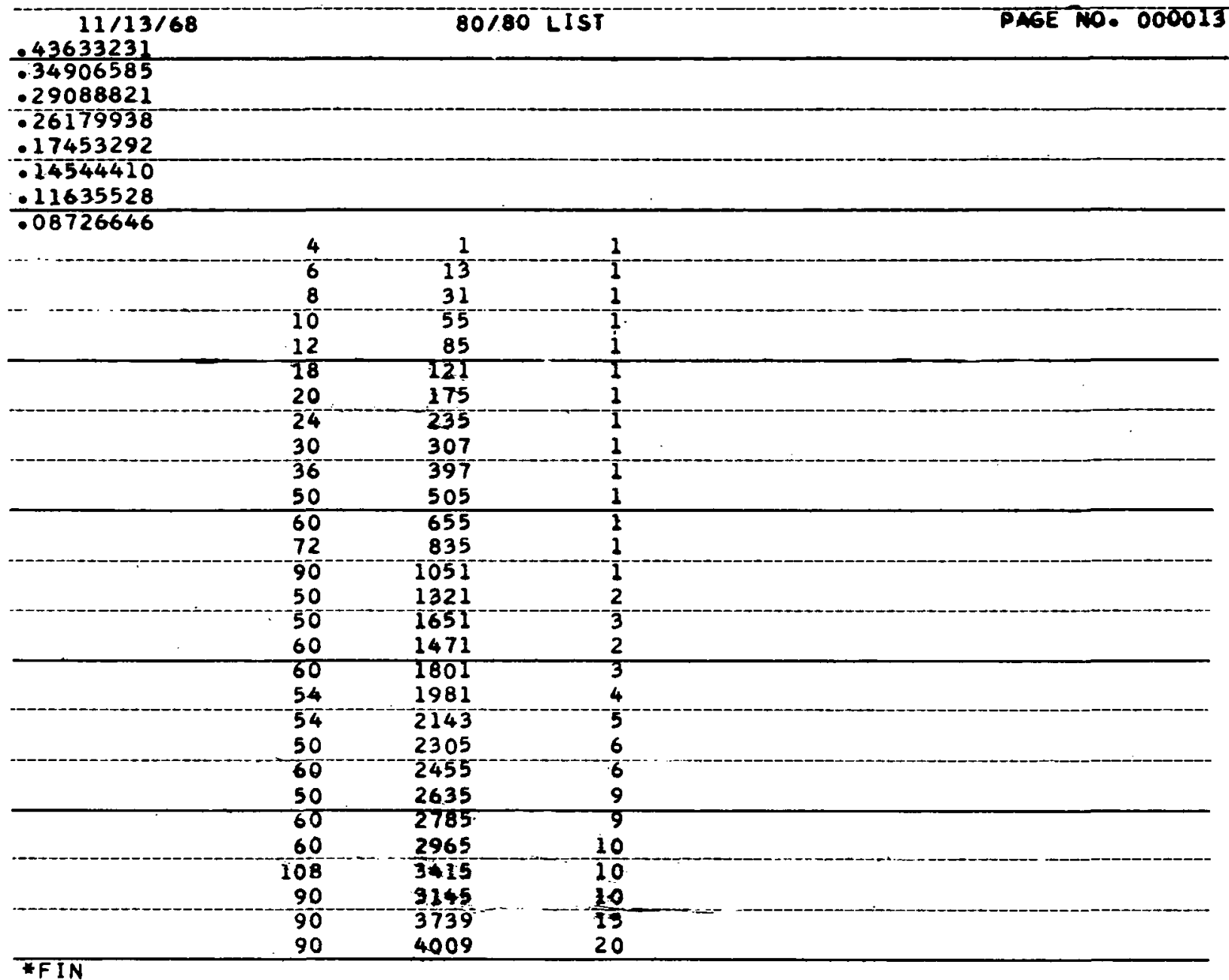




\title{
APPLICATION OF A MODIFIED FAST \\ FOURIER TRANSFORM TO CALCULATE \\ HUMAN OPERATOR DESCRIBING FUNCTION
}

By Richard S. Shirley

Electronics Research Center

\begin{abstract}
A modified fast Fourier transform (FFT) is used in a hybrid computer program to permit processing of tracking data during a run to yield the human operator's describing function almost immediately after the data-taking period. The computer processing time is substantially reduced at no cost in accuracy.
\end{abstract}

STAR Category 08 
"The aronanical and space activities of the United States sball be conducted so as to contribute. . to the expansion of buman knowl. edge of phenoment in the atmosphere and space. The Administration shall provide for the utidest practicable and appropriate dissemination of information concerning its activities and the results thereof."

- National aeronautics And Space ACt of 1958 *

\section{NASA SCIENTIFIC AND TECHNICAL NBLICATIONS,}

TECHNICAL REPORTS: Scientific and technical information considered important, complete, and a lasting contribution to existing knowledge.

TECHNICAL NOTES: Information less broad in scope but nevertheless of importance as a contribution to existing knowledge.

TECHNICAL MEMORANDUMS:

Information receiving limited distribution because of preliminary data, security classification, or other reasons.

CONTRACTOR REPORTS: Scienrific and technical information generated under a NASA contract or grant and considered an important contribution to existing knowledge.
TECHNICAL TRANSLATIONS: Information published in a foreign language considered

* to merit NASA distribation in English.

SPECIAL PUBLICATIONS: Information derived from or of value to NASA activiries. Publications include conference proceedings, monographs, data compilations, handbooks, sourcebooks, and special bibliographies.

TECHNOLOGY UTILIZATION

PUBLICATIONS: Information on technology used by NASA that may be of particular interest in commercial and other non-aerospace applications. Publications include Tech Briefs, Technolugy Utilization Reports and Notes, and Technology Surveys.

Detaits on the availablity of these publications may be obtained from:

SCIENTIFIC AND TECHNICAL INFORMATION DIVISION NATIONAL AERONAUTICS AND SPACE ADMINISTRATION Washington, D.C, 20546 